\title{
Interactive comment on "Reproducing an extreme flood with uncertain post-event information" by Diana Fuentes-Andino et al.
}

\section{Anonymous Referee \#1}

Received and published: 16 October 2016

The manuscript present an interesting work aiming at calibrating a series of rainfallrunoff and hydraulic models against data collected after the 1998 extreme flood occurred in the town of Tegucigalpa, the capital city of Honduras, flood induced by the Hurricane Mitch. Post-event surveys after large flood events have become more frequent over the years and are often based on the combination of field observations and hydrological and hydraulic modelling as a support for data interpretation (see Borga et al, 2008 for instance cited in the paper). The use of a Bayesian model calibration framework makes the originality of the presented manuscript. It can help to better assess to which extent post event survey data may or not help to constrain the values of the parameters of the models (i.e. may help to learn something about the behavior of the watersheds and the river network summarized in the values of the model parameters). If the idea of using a Bayesian calibration framework is interesting, its 
implementation and the analyses of the results could be improved and deepened a lot. In a way, the impression is that the authors did only make part of the work : they did implement the framework and obtained results that are described but not really analyzed in the manuscript, but did not really put into question the procedure used, the associated score function and its influence on the obtained results. They do neither draw clear conclusions about what the event revealed or not about the hydrological or hydraulic processes. It seems, as illustrated by the title and the abstract that the authors are happy to have been able to reproduce the observed discharges and water level based on models. But this is not a surprise according to the large number of model parameters and the limited number of observed data and their inaccuracy. The problem was clearly over-parameterized which is illustrated by the remaining range of possible values for simulation results and parameter values (fig. 5-7). My feeling is that the methodology and its implementation did divert the authors from the real objective: analyzing post-flood data. This is why I did suggest major revisions for this manuscript that should provide both : critical analysis of the available post-event dada and more in-depth analysis of the proposed method and of the obtained results. Here are some questions raised by the presented results:

1) The post-event data set is extremely limited and uncertain. The stage-discharge relation is controlled locally by roughness coefficients. Uncertainties in discharge estimates will directly affect estimates of roughness coefficients and the inverse is also true. This indetermination can only be solved if other type of information is used: existing direct discharge measurements, flood wave propagation velocities (as suggested o p14 $\mathrm{L} \mathrm{16)}$. The available information is dense for the downstream $10 \mathrm{~km}$ river reaches. At least, a specific calibration of the hydraulic model could have been conducted using the information of points 2 and 8 or points 3,6 and 7 (see figure 2), for a better assessment of hydraulic parameters.

2) All data cannot be considered as of equivalent value. Only 3 out of the 6 peak discharge estimates can be considered as based of field surveys. Discharge estimates 4

Interactive

Printer-friendly version

Discussion paper 
to 7 in table 1 are the result of the application of simple rainfall-runoff analysis. They should ideally not have been considered in the calibration procedure or with much larger uncertainties than the other indirect discharge estimates. Two additional estimates seem to have been available (peak outflow of Los Laureles dam and complete outflow hydrograph of the Conception reservoir. Why were these two values, probably relatively accurate if compared to other estimates, not used?

3) The consistency between the various post-event data should be checked either prior to their use for model calibration or even in the Bayesian procedure. This is true for peak discharge estimates upstream and downstream confluences $(8,5,4,6)$ as well as for the high water marks a description of these marks (number, location) is missing in the manuscript).

4) The real efficiency of a global calibration procedure as proposed in the manuscript is questionable. The important features for the calibration may be different for each model (hydrological or hydraulic) and parameters. At least the weight given to each information in the score function should be put in question (a sensitivity analysis could be conducted).

5) Moreover, the number of calibrated parameters appears high and the correlation between these parameters may play an important role and reduce the capacity to narrow significantly the range for the posterior distributions. The number and range of possible values could be more limited for some parameters (again a sensitivity analysis could be useful). The correlation and dependence of the parameter values is an output of the Glue method: why is it not presented and commented? By the way, I wonder why the Glue procedure is still used in place of existing more elaborated Bayesian approaches : Bayesian MCMC (Gibbs algorithm for instance)...

6) The conclusions drawn in section 5 should remain prudent. The limited information about rain amounts and rates (2 gauges for a $800 \mathrm{~km} 2$ watershed) set a major limit to the whole study. Moreover there is clearly compensation between the introduced

Printer-friendly version

Discussion paper 
rainfall multiplier and the parameters of the $R R$ model that is complex to decipher ( $p$ 11, L 25).

7) The discussion part mentions some disagreements between model ouputs and observations that seem not to have been further analyzed: a) under-prediction of water levels (where? Are the water marks isolated, consistent with the surrounding marks or is there a specific problem for some reaches?), b) under-estimation of water levels at the Chiquito river but apparently over-estimation of discharges. The authors suggest some possible explanations P15, L5, but it is their duty to produce more than results and conjectures, but provide also explanations. Is the considered discharge estimate for the Chiquito river, probably the RR simulated discharge (see upstream comment), really accurate and consistent with the other estimate available upstream? A critical analysis of the data is unavoidable in such a study.

Interactive comment on Hydrol. Earth Syst. Sci. Discuss., doi:10.5194/hess-2016-496, 2016. 